\title{
Effects of straw incorporation on nitrogen absorption of split fertilizer applications and on rice growth
}

\author{
Jicheng Zheng ${ }^{1,2}$, Gang Zhang ${ }^{1}$, Dejian Wang ${ }^{1 *}$, Zhiqiang Cao ${ }^{1,2}$, Can Wang ${ }^{1}$, Dezhi Yan ${ }^{3}$ \\ ${ }^{1}$ Institute of Soil Science, Chinese Academy of Sciences, Nanjing, 210008, P.R. China, ${ }^{2}$ University of Chinese Academy of Sciences, Beijing, \\ 100000, P.R. China, ${ }^{3}$ School of Geographic Science, Nantong University, Nantong, 226019, P.R. China
}

\section{A B S TR A C T}

A greenhouse experiment investigated the effect and mechanism of straw incorporation $\left(0\right.$ and $\left.6 \mathrm{t} \mathrm{ha}^{-1}\right)$ on the absorption of fertilizer nitrogen (N) of split applications and on the growth of rice shoots and roots. $\mathrm{N}$ fertilizer was split into: (1) base fertilizer (BF), incorporated before transplanting; (2) tillering fertilizer (TF), broadcasted at tillering stage; and (3) panicle-formation fertilizer (PF), broadcasted at panicle-formation stage. ${ }^{15} \mathrm{~N}$-urea was used as one of three splits. To evaluate the hypothesis that straw incorporation influences the ${ }^{15} \mathrm{~N}$ absorption of one split by enhancing ${ }^{15} \mathrm{~N}$ immobilization or changing root growth, we measured the ${ }^{15} \mathrm{~N}$ residual rate in soil at maturity and root growth throughout the rice-growing season. Straw incorporation significantly decreased ${ }^{15} \mathrm{~N}$ absorption of BF, accompanied by significantly higher ${ }^{15} \mathrm{~N}$ immobilization in soil than in the no-straw treatment. However, straw incorporation significantly increased ${ }^{15} \mathrm{~N}$ absorption of top-dressing (both TF and PF), accompanied by significantly greater dry matter and length of surface roots (0-5 $\mathrm{cm}$ depth) throughout the rice-growing season (top-dressing ${ }^{15} \mathrm{~N}$ was seldom found in soils $>5 \mathrm{~cm}$ ). Shoot dry matter with straw incorporation decreased significantly in the early stage but increased in the late stage, compared with the no-straw treatment, and shoot total $\mathrm{N}$ with straw incorporation decreased significantly throughout the rice-growing season (this negative effect had decreased by the late stage). To better synchronize $\mathrm{N}$ supply with rice demand and reduce the risk of water eutrophication, $\mathrm{N}$ levels of BF and top-dressing should be reviewed when straw is incorporated.

Keywords: Fertilizer $\mathrm{N}$ recovery; ${ }^{15} \mathrm{~N}$ tracer; Rice growth; Split nitrogen application; Straw incorporation

\section{INTRODUCTION}

Rice (Oryza sativa L.), a food staple, is widely cultivated, especially in East Asia, Southeast Asia and South Asia. In recent years, concern about development of the social economy in these places has been joined by concerns about air quality and soil fertility, resulting in a change in the management of crop straw in rice-based cropping systems. Historically, straw management required almost complete removal or burning of the straw after crop harvest. This is not good for the sustainable productivity of the soil, because crop straw plays an essential role in nutrient cycling and is a source of carbon (C) (Yadvinder-Singh et al., 2005). Burning crop straw results in considerable air pollution and thus aggravates the already serious environmental problems in these regions (Tiwari et al., 2016; Zhang et al., 2016).

The new method of managing crop straw is to apply it to the rice field, but this also creates some novel problems (Yadvinder-Singh et al., 2005; Xia et al., 2014, 2018). One of the most important of these is $\mathrm{N}$ immobilization, caused by straw decomposition. To offset this, farmers prefer to increase applications of $\mathrm{N}$ fertilizer; however, this is not only uneconomic, but also induces or aggravates the risk of water eutrophication (Fageria et al., 2003). It is generally known that $\mathrm{N}$ is not only usually the most limiting nutrient in rice production, but also the main element in water eutrophication (Fageria et al., 2003). Clearly, only after we understand how straw application affects the uptake of $\mathrm{N}$ fertilizer can we apply $\mathrm{N}$ fertilizer appropriately to meet rice demand while protect the quality of the environment: that is, avoiding yield reduction caused by shortages of $\mathrm{N}$ fertilizer (Koffi et al., 2016; Wang, et al., 2018) and pollution due to its oversupply.

The ${ }^{15} \mathrm{~N}$ isotope tracer technique has allowed many researchers to study the relationship between the fertilizer $\mathrm{N}$ recovery in plants $\left(\mathrm{FNR}_{\mathrm{p}}\right.$ ) and application of straw in the rice-growing season. For example, when the $\mathrm{N}$ fertilizer was all applied as base fertilizer (BF), there was 
significant negative effect of straw application on $\mathrm{FNR}_{\mathrm{p}}$ (Masayna et al., 1985; Huang and Broadbent, 1989). When the $\mathrm{N}$ fertilizer was split applied (BF and at least one topdressing), Chen et al. (2010) reported that application of straw decreased the FNR slightly and insignificantly, and there were even reports that application of straw could increase the FNR a little (Wang et al., 2004; Yu, 2012). Based on these observations, we hypothesized that, when $\mathrm{N}$ fertilizer was split applied, the application of straw may have different effects on the FNR of BF and top-dressing. However, there is little information on the effects of straw application on the $\mathrm{FNR}_{\mathrm{p}}$ of each split when the $\mathrm{N}$ fertilizer is split applied.

We hypothesized that straw incorporation influences the FNR of BF or top-dressing by enhancing $\mathrm{N}$ immobilization or changing root growth. However, there are three differences between BF and top-dressing. (1) Unlike BF, which is incorporated into soil in the same way as straw, top-dressing is broadcasted into floodwater. Straw incorporation may have different effects on the $\mathrm{N}$ immobilization of $\mathrm{BF}$ and top-dressing. (2) Both straw and $\mathrm{BF}$ are applied before rice transplanting; however, top-dressing is applied during the rice-growing season. Straw decomposition may have different effects on the $\mathrm{N}$ immobilization of $\mathrm{BF}$ and top-dressing. (3) Many researchers (Phongpan and Mosier, 2003ab; Linquist et al., 2009) have reported that top-dressing $\mathrm{N}$ seldom moves downward into the subsurface soil (depth $\geq 5 \mathrm{~cm}$ in soil), so its absorption must have a closer relationship with surface roots $(0-5 \mathrm{~cm}$ depth) than with subsurface roots; however, for absorption of $\mathrm{BF}$, both subsurface and surface roots are important. Straw incorporation may have different effects on the growth of surface roots and subsurface roots.

The middle-lower basin of the Huaihe River, China, is an important rice-wheat crop rotation area. As increasing numbers of small farmers move from agriculture into non-agricultural industries, the large-scale management of agriculture has become inevitable, and makes it easy to deal with the problems caused by straw application and misuse of $\mathrm{N}$ fertilizer. In the rice season of the middlelower basin of the Huaihe River, the common practice of straw incorporation and $\mathrm{N}$ fertilizer application have the following characteristics. (1) There is little decomposition of the straw before the rice is transplanted, because of the short fallow (usually 1-5 days) in the rice-wheat rotation system (summer rice-winter wheat). (2) The common practice for $\mathrm{N}$ fertilization in this area is 3-split application (no matter whether straw is incorporated or not). The first split is incorporated into the soil before rice transplanting (known as BF); the remaining two splits are broadcasted into the floodwater, one at the tillering stage (tillering fertilizer, TF), and the other at the panicle-formation stage (panicle-formation fertilizer, PF).

In this study an ${ }^{15} \mathrm{~N}$ isotope tracer technique was used to conduct a rice-growing greenhouse experiment with the following objectives: (1) to evaluate the hypothesis that the application of straw may have different effects on the $\mathrm{FNR}_{\mathrm{p}}$ of $\mathrm{BF}$ and top-dressing (TF and PF); and (2) to evaluate the hypothesis that straw incorporation influences the $\mathrm{N}$ absorption of BF or top-dressing by enhancing $\mathrm{N}$ immobilization or changing root growth.

\section{MATERIALS AND METHODS}

\section{Site description and soil preparation}

The soil used for the pot experiment was sampled at Hongxing village $\left(33^{\circ} 44^{\prime} 32^{\prime \prime} \mathrm{N}, 118^{\circ} 38^{\prime} 47^{\prime \prime} \mathrm{E}\right)$, Siyang county, Jiangsu province, China. This typical soil of the middle-lower basin of the Huaihe River was developed from alluvial deposits and classified as Fluvo-aquic according to the Chinese soil classification system (Standardization Administration of the People's Republic of China, 2009). It was collected from the plow horizon (0-20 cm depth) of a harvested wheat field managed under a continuous two-cropping system (summer ricewinter wheat) for more than 20 years. After removal of vegetation and visible roots, the soil was air dried, ground, sieved $(<1.7 \mathrm{~mm})$ and homogenized. Properties of the soil were $\mathrm{pH} 6.48$ (tested in a sample containing a 1:2.5 ratio of soil to water), organic C $11.1 \mathrm{~g} \mathrm{~kg}^{-1}\left(\mathrm{~K}_{2} \mathrm{Cr}_{2} \mathrm{O}_{7^{-}}\right.$ volumetric method), total $\mathrm{N}$ (TN) $1.19 \mathrm{~g} \mathrm{~kg}^{-1}$ (Kjeldahl method), Olsen-P $38.3 \mathrm{mg} \mathrm{kg}^{-1}$ (spectrophotometry after $\mathrm{NaHCO}_{3}$ extraction), exchangeable $\mathrm{K} 101 \mathrm{mg} \mathrm{kg}^{-1}$ (flame photometry after $\mathrm{NH}_{4} \mathrm{OAc}$ extraction), clay $27.1 \%$, silt $35.9 \%$ and sand $37.0 \%$.

The pot experiment was carried out under outdoor conditions, but was moved into a glasshouse to keep out rain at the Institute of Soil Science, CAS, Nanjing, China $\left(32^{\circ} 03^{\prime} \mathrm{N}, 118^{\circ} 47^{\prime} \mathrm{E}\right), 180 \mathrm{~km}$ south of the sampling site, from June to October 2015. The experimental site has a humid subtropical monsoon climate with an average annual temperature of $15.9^{\circ} \mathrm{C}$ and an average annual precipitation of $1090 \mathrm{~mm}$, quite similar to the soil sampling site of Hongxing village.

\section{Experiment design}

The split-plot design of the pot experiment is shown in Table 1. The main treatments were no-straw treatment and straw-incorporation treatment. The subsidiary treatments were four different patterns of ${ }^{15} \mathrm{~N}$-urea application: (1) all three splits of $\mathrm{N}$ fertilizer used normal ${ }^{14} \mathrm{~N}$-urea; (2) BF used ${ }^{15} \mathrm{~N}$-urea (the other two splits used normal ${ }^{14} \mathrm{~N}$-urea); (3) $\mathrm{TF}$ 
Table 1: Experimental treatments and sampling

\begin{tabular}{|c|c|c|c|c|c|}
\hline \multirow[t]{2}{*}{ Treatment } & \multicolumn{3}{|c|}{ N split application (240 kg ha-1) } & \multicolumn{2}{|l|}{ Sampling } \\
\hline & $\mathrm{BF}^{\mathrm{a}}(50 \%)$ & TF (10\%) & PF (40\%) & Time $^{\mathrm{b}}$ & Object \\
\hline \multicolumn{6}{|l|}{ No straw } \\
\hline${ }^{14} \mathrm{~N}$ & ${ }^{14} \mathrm{~N}$-urea ${ }^{\mathrm{C}}$ & ${ }^{14} \mathrm{~N}$-urea & ${ }^{14} \mathrm{~N}$-urea & TF, PF, flowering & shoot, root \\
\hline${ }^{15} \mathrm{NBF}$ & ${ }^{15} \mathrm{~N}$-urea & ${ }^{14} \mathrm{~N}$-urea & ${ }^{14} \mathrm{~N}$-urea & $T F+7 d, P F+7 d$, maturity & shoot, soil (maturity) \\
\hline${ }^{15} \mathrm{NTF}$ & ${ }^{14} \mathrm{~N}$-urea & ${ }^{15} \mathrm{~N}$-urea & ${ }^{14} \mathrm{~N}$-urea & $T F+7 d, P F+7 d$, maturity & shoot, soil (maturity) \\
\hline${ }^{15} \mathrm{NPF}$ & ${ }^{14} \mathrm{~N}$-urea & ${ }^{14} \mathrm{~N}$-urea & ${ }^{15} \mathrm{~N}$-urea & $P F+7 d$, maturity & shoot, soil (maturity) \\
\hline \multicolumn{6}{|c|}{ Straw incorporation } \\
\hline${ }^{14} \mathrm{~N}+\mathrm{S}$ & ${ }^{14} \mathrm{~N}$-urea & ${ }^{14} \mathrm{~N}$-urea & ${ }^{14} \mathrm{~N}$-urea & TF, PF, flowering & shoot, root \\
\hline${ }^{15} \mathrm{NBF}+\mathrm{S}$ & ${ }^{15} \mathrm{~N}$-urea & ${ }^{14} \mathrm{~N}$-urea & ${ }^{14} \mathrm{~N}$-urea & $\mathrm{TF}+7 \mathrm{~d}, \mathrm{PF}+7 \mathrm{~d}$, maturity & shoot, soil (maturity) \\
\hline${ }^{15} \mathrm{NTF}+\mathrm{S}$ & ${ }^{14} \mathrm{~N}$-urea & ${ }^{15} \mathrm{~N}$-urea & ${ }^{14} \mathrm{~N}$-urea & $T F+7 d, P F+7 d$, maturity & shoot, soil (maturity) \\
\hline${ }^{15} \mathrm{NPF}+\mathrm{S}$ & ${ }^{14} \mathrm{~N}$-urea & ${ }^{14} \mathrm{~N}$-urea & ${ }^{15} \mathrm{~N}$-urea & $P F+7 d$, maturity & shoot, soil (maturity) \\
\hline
\end{tabular}

${ }^{a} \mathrm{BF}$, base fertilizer; TF, tillering fertilizer; $\mathrm{PF}$, panicle-formation fertilizer. ${ }^{\mathrm{b}}$ The corresponding times of $\mathrm{BF}, \mathrm{TF}, \mathrm{PF}$, flowering and maturity were-1, $7,47,85$ and 130 days after transplanting (DAT). ${ }^{c}{ }^{14} \mathrm{~N}$-urea, normal urea; ${ }^{15} \mathrm{~N}$-urea, ${ }^{15} \mathrm{~N}$-labeled urea with $30 \%$ isotope abundance

used ${ }^{15} \mathrm{~N}$-urea (the other two splits used normal ${ }^{14} \mathrm{~N}$-urea); and (4) PF used ${ }^{15} \mathrm{~N}$-urea (the other two splits used normal ${ }^{14} \mathrm{~N}$-urea). There were a total of eight treatments: ${ }^{14} \mathrm{~N}$, ${ }^{15} \mathrm{NBF},{ }^{15} \mathrm{NTF}$ and ${ }^{15} \mathrm{NPF}$ for no-straw treatment; ${ }^{14} \mathrm{~N}+\mathrm{S}$, ${ }^{15} \mathrm{NBF}+\mathrm{S},{ }^{15} \mathrm{NTF}+\mathrm{S}$ and ${ }^{15} \mathrm{NPF}+\mathrm{S}$ for straw-incorporation treatment. The wheat straw (Triticum aestivum L.) used in this experiment was ground to pass through a $0.841-\mathrm{mm}$ sieve. The organic $\mathrm{C}$ and TN contents of the straw were $473.4 \mathrm{~g} \mathrm{~kg}^{-1}$ and $5.16 \mathrm{~g} \mathrm{~kg}^{-1}$, respectively. The $\mathrm{N}$ fertilizer, at the usual rate of $240 \mathrm{~kg} \mathrm{ha}^{-1}$, was divided into three splits for both the no-straw treatment and straw-incorporation treatment: (1) $50 \%$ incorporated into the soil 1 day before rice transplanting $(\mathrm{BF})$; (2) 10\% broadcasted at tillering stage (TF); and (3) 40\% broadcasted at panicle-formation stage (PF). ${ }^{15} \mathrm{~N}$-labeled urea with 30\% isotope abundance was used to obtain the FNR for the different splits. Normal urea, $\mathrm{Na}_{2} \mathrm{HPO}_{4}$ and $\mathrm{KCl}$ were applied to supply $\mathrm{N}$, phosphorus $(\mathrm{P})$ and potassium $(\mathrm{K})$, respectively.

Experimental pots, made from polyvinyl chloride (PVC) tubes $(24 \mathrm{~cm}$ internal diameter $\times 30 \mathrm{~cm}$ high), were filled with $12 \mathrm{~kg}$ air-dried soil to a depth of $20 \mathrm{~cm}$ after flooding. For the straw-incorporation treatment, each pot received $27 \mathrm{~g}$ wheat straw $\left(6 \mathrm{tha}^{-1}\right.$, which was calculated by the straw weight divided by the area of the pot. The same method was used to calculate the amount of NPK fertilizer) and $0.55 \mathrm{~g} \mathrm{~N}\left(120 \mathrm{~kg} \mathrm{ha}^{-1}\right), 0.271 \mathrm{~g} \mathrm{P}\left(60 \mathrm{~kg} \mathrm{ha}^{-1}\right)$ and $0.271 \mathrm{~g}$ $\mathrm{K}\left(60 \mathrm{~kg} \mathrm{ha}^{-1}\right)$ as basal fertilization. For the no-straw treatment, application of straw was omitted. The straw and fertilizers were mixed well with soil and submerged on 25 June 2015. The next day, 30-day-old rice seedlings of a common cultivar (Nanjing-46) were transplanted at the rate of three hills per pot with two seedlings per hill. The pots were surrounded by guard rows to ensure every pot received the same amount of sunshine. The guard rows comprised pots whose establishment and plant cultivation were identical to the no-straw treatment. The TF and PF were applied in solution to the floodwater at 7 and 47 days after transplanting (DAT), respectively. Intensive pest and weed management was achieved by using a combination of pesticides and manual weed control.

\section{Sampling and measurements}

According to the different subsidiary treatments, sampling was divided into four groups. (1) Group I $\left({ }^{14} \mathrm{~N},{ }^{14} \mathrm{~N}+\mathrm{S}\right)$ : all three splits used normal ${ }^{14} \mathrm{~N}$-urea. We had 12 pots for destructive sampling on three occasions: 7 DAT (TF), 47 DAT (PF) and 85 DAT (flowering). (2) Group II $\left({ }^{15} \mathrm{NBF}\right.$, $\left.{ }^{15} \mathrm{NBF}+\mathrm{S}\right)$ : $\mathrm{BF}$ used ${ }^{15} \mathrm{~N}$-urea. We had 12 pots for destructive sampling on three occasions: $14 \mathrm{DAT}$ (TF+7d), $54 \mathrm{DAT}$ $(\mathrm{PF}+7 \mathrm{~d})$ and $130 \mathrm{DAT}$ (maturity). (3) Group III $\left({ }^{15} \mathrm{NTF}\right.$, $\left.{ }^{15} \mathrm{NTF}+\mathrm{S}\right)$ : TF used ${ }^{15} \mathrm{~N}$-urea. We had 12 experimental pots for destructive sampling on three occasions: 14 DAT (TF+7d), $54 \mathrm{DAT}(\mathrm{PF}+7 \mathrm{~d})$ and $130 \mathrm{DAT}$ (maturity). (4) Group IV $\left({ }^{15} \mathrm{NPF},{ }^{15} \mathrm{NPF}+\mathrm{S}\right)$ : PF used ${ }^{15} \mathrm{~N}$-urea. We had 8 pots for destructive sampling on two occasions: 54 DAT $(\mathrm{PF}+7 \mathrm{~d})$ and $130 \mathrm{DAT}$ (maturity).

Rice roots were sampled for Group I $\left({ }^{14} \mathrm{~N},{ }^{14} \mathrm{~N}+\mathrm{S}\right)$. The total roots in the $0-20 \mathrm{~cm}$ soil layer were partitioned into surface roots and subsurface roots. Both were collected by sectioning the soil column into two layers $(0-5 \mathrm{~cm}$ and $5-20 \mathrm{~cm})$ and washing the roots free from soil and straw residues. The roots from these two layers were taken into the laboratory for measurement of root length using the software package WinRHIZO 4.1 (Regent Instruments Inc., Quebec, Canada, 2000). These roots were then dried at $70^{\circ} \mathrm{C}$ to constant weight to obtain the dry matter (DM) of each individual layer.

We sampled the rice shoots of all four groups $\left({ }^{14} \mathrm{~N},{ }^{14} \mathrm{~N}+\mathrm{S}\right.$; ${ }^{15} \mathrm{NBF},{ }^{15} \mathrm{NBF}+\mathrm{S} ;{ }^{15} \mathrm{NTF},{ }^{15} \mathrm{NTF}+\mathrm{S}$; and $\left.{ }^{15} \mathrm{NPF},{ }^{15} \mathrm{NPF}+\mathrm{S}\right)$. The shoot samples were dried at $70^{\circ} \mathrm{C}$ to constant weight to obtain the DM, and then powdered $(<0.147 \mathrm{~mm})$ to analyze ${ }^{15} \mathrm{~N}$ abundance and TN content. ${ }^{15} \mathrm{~N}$ abundance values were determined by an isotope ratio mass spectrograph (Mat-253, USA). The TN content of shoot samples was determined by the Kjeldahl method using the automatic $\mathrm{N}$ determination system (Lu, 2014). 
The soils of Groups II, III and IV $\left({ }^{15} \mathrm{NBF},{ }^{15} \mathrm{NBF}+\mathrm{S}\right.$; ${ }^{15} \mathrm{NTF},{ }^{15} \mathrm{NTF}+\mathrm{S}$; and ${ }^{15} \mathrm{NPF},{ }^{15} \mathrm{NPF}+\mathrm{S}$ ) were sampled at maturity to obtain the ${ }^{15} \mathrm{~N}$ residual rate. For those treatments using ${ }^{15} \mathrm{~N}$-urea as TF or PF $\left({ }^{15} \mathrm{NTF},{ }^{15} \mathrm{NTF}+\mathrm{S}\right.$; ${ }^{15} \mathrm{~N}-\mathrm{PF}$; and $\left.{ }^{15} \mathrm{NPF}+\mathrm{S}\right)$, the soil samples were divided into surface soil samples $(0-5 \mathrm{~cm}$ depth) and subsurface soil samples (5-20 cm depth). For the treatments using ${ }^{15} \mathrm{~N}$-urea as $\mathrm{BF}\left({ }^{15} \mathrm{NBF} ;{ }^{15} \mathrm{NBF}+\mathrm{S}\right)$, the soil samples were not sectioned into two layers. After removing visible roots, the soil samples were weighed, thoroughly mixed, and analyzed for $\mathrm{TN}$ content and ${ }^{15} \mathrm{~N}$ abundance. The ${ }^{15} \mathrm{~N}$ abundance was determined by a Mat-253 mass spectrograph. The TN content of the soil was determined by the Kjeldahl method using the automatic $\mathrm{N}$ determination system (Lu, 2014).

\section{Calculations and statistical analysis}

The fertilizer $\mathrm{N}$ recovery in plants $\left(\mathrm{FNR}_{\mathrm{p}}\right)$ was calculated using the following equation (Yang et al., 2013) (Eqn 1):

$$
\operatorname{FNR}_{\mathrm{p}}(\%)=\frac{\mathrm{TN}_{\mathrm{p}} \times{ }^{15} \mathrm{~N}_{\mathrm{p} \text {-excess }}}{\mathrm{TN}_{\mathrm{f}} \times{ }^{15} \mathrm{~N}_{\text {f-excess }}} \times 100
$$

where $\mathrm{TN}_{\mathrm{p}}$ is the $\mathrm{TN}$ of the shoot sample, $\mathrm{TN}_{\mathrm{f}}$ is the $\mathrm{TN}$ of the fertilizer, ${ }^{15} \mathrm{~N}_{\text {p-excess }}$ is the atom $\%{ }^{15} \mathrm{~N}$ excess from background level in the shoot sample and ${ }^{15} \mathrm{~N}_{\text {f-excess }}$ is the atom $\%{ }^{15} \mathrm{~N}$ excess from background level in the $\mathrm{N}$ fertilizer.

The residual rate of fertilizer $\mathrm{N}$ in the soil was calculated as ${ }^{15} \mathrm{~N}$ recovery of ${ }^{15} \mathrm{~N}$-labeled urea in the soil sample, according to the following equation (Yang et al., 2013) (Eqn 2):

Residual rate $(\%)=\frac{\mathrm{TN}_{\mathrm{s}} \times{ }^{15} \mathrm{~N}_{\mathrm{s} \text {-excess }}}{\mathrm{TN}_{\mathrm{f}} \times{ }^{15} \mathrm{~N}_{\mathrm{f}-\text { excess }}} \times 100$

where $\mathrm{TN}_{\mathrm{S}}$ is the $\mathrm{TN}$ of the soil sample, $\mathrm{TN}_{\mathrm{f}}$ is the $\mathrm{TN}$ of the fertilizer, ${ }^{15} \mathrm{~N}_{\text {s-excess }}$ is the atom $\%{ }^{15} \mathrm{~N}$ excess from background level in the soil sample and ${ }^{15} \mathrm{~N}_{\text {fexcess }}$ is the atom $\%{ }^{15} \mathrm{~N}$ excess from background level in the $\mathrm{N}$ fertilizer.

All statistical analyses were conducted using SPSS 20.0 (2011, IBM, New York, USA) and the figures were created using SigmaPlot 10.0 (2006, Systat Software, SanJose, USA). Following plant sampling and measuring (DM and TN of shoots; DM and length of surface roots, subsurface roots and total roots; and $\mathrm{FNR}_{\mathrm{p}}$ of separate split), a Student's t test at $P<0.05$ was conducted to test the significance between the two straw treatments (Figs 1, 2, 3; Tables 2, 3). To examine the residual rate and loss rate of each split, one-way analysis of variance (ANOVA) at $P<0.05$ was conducted to test the significance between all eight treatments (Table 3).

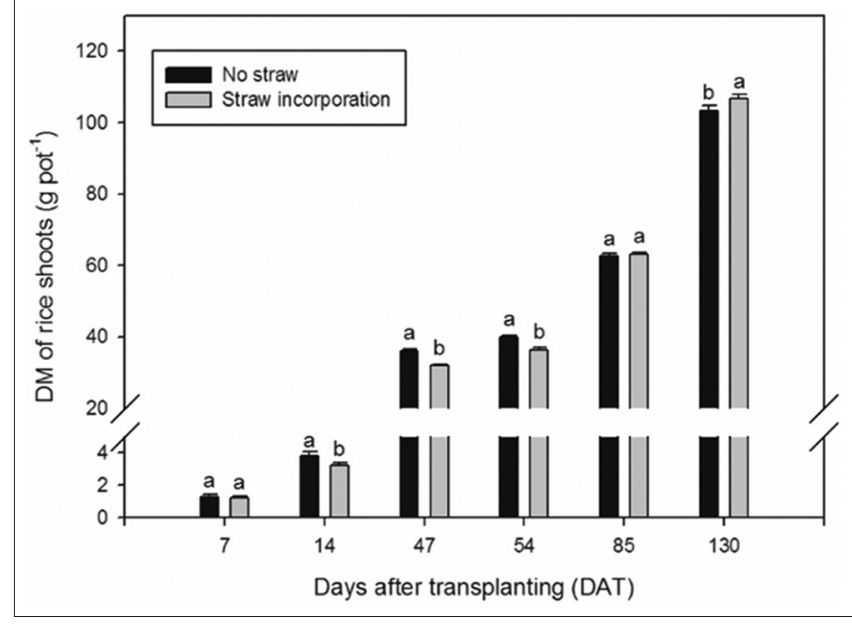

Fig 1. Dry matter (DM) of rice shoots at 7, 14, 47, 54, 85 and 130 DAT.

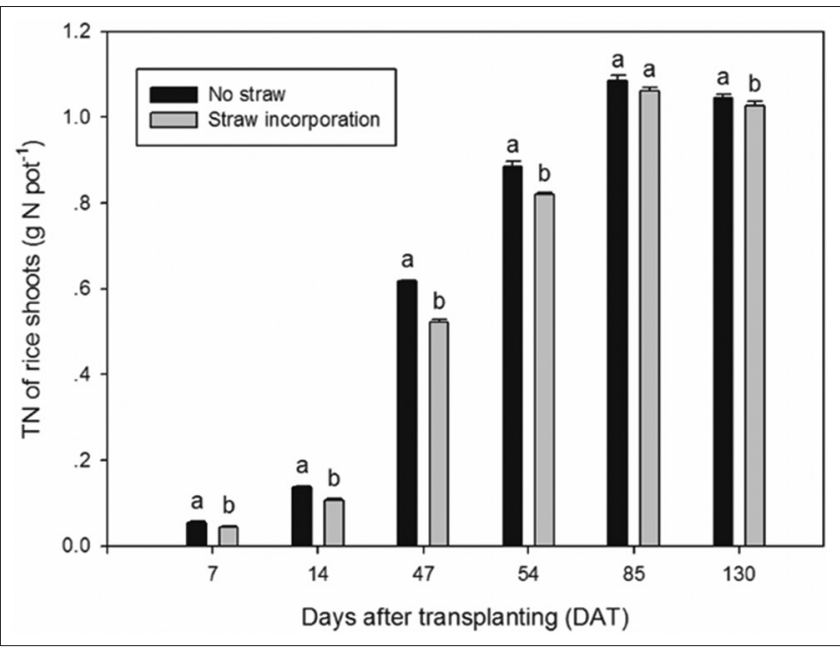

Fig 2. Total Nitrogen (TN) of rice shoots at 7, 14, 47, 54, 85 and 130 DAT.

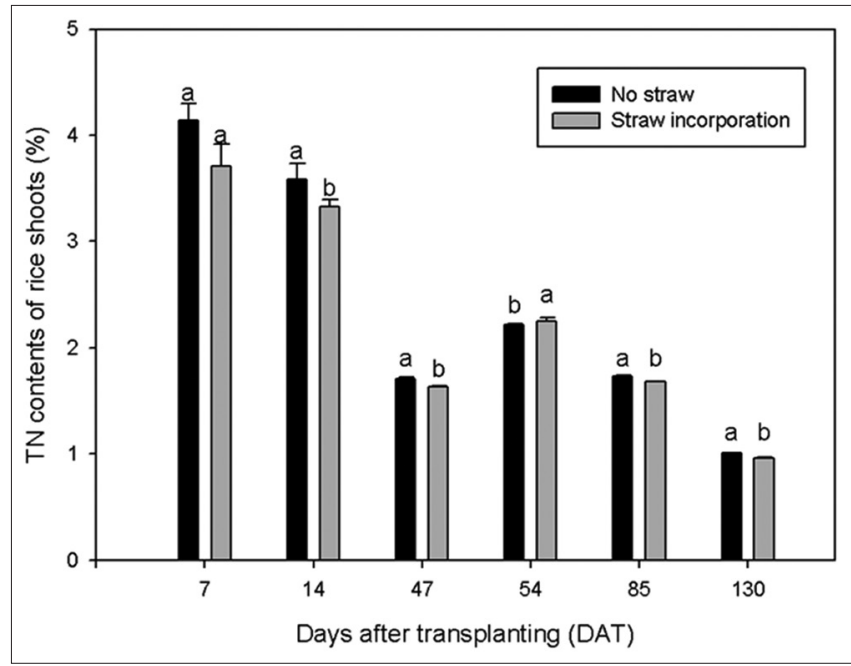

Fig 3. Total Nitrogen contents (TN contents) of rice shoots at 7, 14, 47, 54, 85 and 130 DAT. 
Table 2: Dry matter (DM) and length of rice roots in different layers at 7, 47 and 85 days after transplanting (DAT)

\begin{tabular}{|c|c|c|c|c|c|c|c|}
\hline \multirow[t]{2}{*}{ Root layer } & \multirow[t]{2}{*}{ Straw treatment } & \multicolumn{3}{|c|}{ Root DM $\left(\mathrm{g} \mathrm{pot}^{-1}\right)$} & \multicolumn{3}{|c|}{ Root length (m pot ${ }^{-1}$ ) } \\
\hline & & $7 \mathrm{DAT}^{\mathrm{a}}$ & 47 DAT & 85 DAT & 7 DAT & 47 DAT & 85 DAT \\
\hline Surface roots & No straw & $0.21^{b}$ & $2.45^{\mathrm{b}}$ & $3.59^{b}$ & $66^{b}$ & $505^{b}$ & $395^{b}$ \\
\hline$(0-5 \mathrm{~cm})$ & Straw incorporation & $0.26^{a}$ & $2.81^{\mathrm{a}}$ & $4.02^{\mathrm{a}}$ & $93^{\mathrm{a}}$ & $643^{\mathrm{a}}$ & $517^{a}$ \\
\hline Subsurface roots & No straw & $0.04^{a}$ & $3.23^{a}$ & $4.83^{b}$ & $32^{\mathrm{a}}$ & $533^{a}$ & $679^{b}$ \\
\hline$(5-20 \mathrm{~cm})$ & Straw incorporation & $0.04^{\mathrm{a}}$ & $2.90^{\mathrm{b}}$ & $5.48^{a}$ & $34^{a}$ & $466^{b}$ & $877^{a}$ \\
\hline Total roots & No straw & $0.25^{b}$ & $5.68^{a}$ & $8.42^{b}$ & $98^{b}$ & $1040^{\mathrm{a}}$ & $1070^{\mathrm{b}}$ \\
\hline$(0-20 \mathrm{~cm})$ & Straw incorporation & $0.30^{\mathrm{a}}$ & $5.72^{\mathrm{a}}$ & $9.50^{\mathrm{a}}$ & $127^{a}$ & $1110^{\mathrm{a}}$ & $1390^{\mathrm{a}}$ \\
\hline
\end{tabular}

Values followed by different letters in the same column of the same soil layer indicate significant differences $(P<0.05)$ based on Student's $t$ test. ${ }^{\text {a }} 7,47$ and 85 DAT, corresponding to days of tillering fertilizer (TF), panicle-formation fertilizer (PF) and flowering, respectively

Table 3: Accumulation and balance of split nitrogen application

\begin{tabular}{|c|c|c|c|c|c|c|c|c|}
\hline \multirow[t]{2}{*}{ Fertilizer $\mathbf{N}$ split ${ }^{\mathrm{a}}$} & \multirow[t]{2}{*}{ Straw treatment } & \multicolumn{3}{|c|}{$\mathrm{FNR}_{\mathrm{p}}{ }^{\mathrm{b}}(\%)$} & \multicolumn{3}{|c|}{ Residual rate at maturity (\%) } & \multirow[t]{2}{*}{ Loss rate at maturity $(\%)$} \\
\hline & & 14 DAT $^{c}$ & 54 DAT & 130 DAT & $0-5 \mathrm{~cm}$ & $5-20 \mathrm{~cm}$ & $0-20 \mathrm{~cm}$ & \\
\hline \multirow[t]{2}{*}{ BF } & No straw & $8.8^{a}$ & $29.5^{\mathrm{a}}$ & $30.4^{a}$ & $n^{d}$ & $n^{d}$ & $35.9^{b}$ & $33.7^{e}$ \\
\hline & Straw incorporation & $4.6^{\mathrm{b}}$ & $15.0^{\mathrm{b}}$ & $18.9^{b}$ & $\mathrm{n}^{\mathrm{d}}$ & $\mathrm{n}^{\mathrm{d}}$ & $66.2^{\mathrm{a}}$ & $14.9^{f}$ \\
\hline \multirow[t]{2}{*}{ TF } & No straw & $30.1^{b}$ & $36.9^{b}$ & $22.6^{b}$ & $9.0^{\mathrm{b}}$ & $1.5^{\mathrm{a}}$ & $10.5^{b}$ & $66.9^{a}$ \\
\hline & Straw incorporation & $35.4^{a}$ & $42.0^{\mathrm{a}}$ & $30.3^{a}$ & $18.4^{\mathrm{a}}$ & $1.2^{\mathrm{a}}$ & $19.6^{a}$ & $50.1^{b}$ \\
\hline \multirow[t]{2}{*}{ PF } & No straw & & $45.8^{b}$ & $40.6^{b}$ & $10.2^{\mathrm{b}}$ & $1.7^{\mathrm{a}}$ & $11.9^{a}$ & $47.5^{c}$ \\
\hline & Straw incorporation & & $51.2^{\mathrm{a}}$ & $45.1^{\mathrm{a}}$ & $10.7^{\mathrm{b}}$ & $2.0^{\mathrm{a}}$ & $12.7^{\mathrm{a}}$ & $42.2^{d}$ \\
\hline
\end{tabular}

Values of $\mathrm{FNR}_{\mathrm{p}}$ and residual rate followed by different letters in the same column and of the same $\mathrm{N}$ split indicate significant differences $(P<0.05)$ based on Student's $t$ test; values of loss rate followed by different letters in the same column indicate significant differences $(P<0.05)$ based on one-way analysis of variance (ANOVA). ${ }^{\mathrm{a} B F}$, base fertilizer; $\mathrm{TF}$, tillering fertilizer; $\mathrm{PF}$, panicle-formation fertilizer. ${ }^{\mathrm{b}} \mathrm{BNR}_{\mathrm{P}}$, fertilizer $\mathrm{N}$ recovery in plants. ${ }^{\mathrm{C} D A T}$, days after transplanting; 130 DAT, corresponding day of maturity. ${ }^{d}$ nd, not determined.

\section{RESULTS}

\section{DM, TN and TN contents of rice shoots}

The shoot DM increased with DAT in both straw treatments, with the maximum levels at maturity (130 DAT) (Fig. 1). In the early-stage samplings (7, 14, 47 and 54 DAT), rice grown in pots with straw incorporation produced significantly lower shoot DM than rice grown in the nostraw treatment. However, at 85 DAT (flowering) the shoot DM did not differ between the two treatments; and at 130 DAT (maturity), the shoot DM of the straw-incorporation pots was $3.1 \%$ greater than that of the no-straw pots significantly $(P<0.05)$.

Different letters in the same DAT indicate significant difference at the 0.05 probability level based on Student's $\mathrm{t}$ test. Vertical bars represent \pm standard deviation of the mean ( $\mathrm{n}=4$ at 7, 47 and 85 DAT; $\mathrm{n}=8$ at 14 DAT; and $\mathrm{n}=12$ at 54,130 DAT).

The shoot TN increased continuously from 7 DAT to 85 DAT; maximum levels were reached at $85 \mathrm{DAT}$ (flowering), and there was then a slight decrease toward 130 DAT (maturity) (Fig. 2). Compared with the no-straw treatment, straw incorporation resulted in lower shoot $\mathrm{TN}$ throughout the rice-growing season, but the differences between the two treatments decreased in the late-stage (85-130 DAT).
At maturity, the shoot TN of straw-incorporation treatment was $1.6 \%$ lower than in the no-straw treatment, a slight but significant $(P<0.05)$ result.

Different letters in the same DAT indicate significant difference at the 0.05 probability level based on Student's $\mathrm{t}$ test. Vertical bars represent \pm standard deviation of the mean ( $\mathrm{n}=4$ at 7, 47 and 85 DAT; $\mathrm{n}=8$ at 14 DAT; and $\mathrm{n}=12$ at 54,130 DAT).

The TN contents of shoots generally showed a decreasing trend in both straw treatments, with the minimum levels at maturity (130 DAT) (Fig. 3). For most of the rice-growing season, straw incorporation significantly decreased the TN contents; however at $54 \mathrm{DAT}(\mathrm{PF}+7 \mathrm{~d})$, the TN content of the straw-incorporation treatment was significantly higher than that of the no-straw treatment $(P<0.05)$.

Different letters in the same DAT indicate significant difference at the 0.05 probability level based on Student's $\mathrm{t}$ test. Vertical bars represent \pm standard deviation of the mean ( $\mathrm{n}=4$ at 7, 47 and 85 DAT; $\mathrm{n}=8$ at 14 DAT; and $\mathrm{n}=12$ at 54, 130 DAT).

\section{DM and length of rice roots in different layers}

In both straw treatments the DM of surface roots increased with time from 7 DAT (TF) to 85 DAT (flowering) 
sampling, while the length of surface roots increased from 7 DAT to 47 DAT (PF) and decreased toward 85 DAT (Table 2). In comparison to the no-straw treatment, straw incorporation showed consistently significantly higher DM and length of surface roots at all three sampling times (TF, PF and flowering) $(P<0.05)$.

The DM and length of subsurface roots increased over time in both straw treatments, with the highest value at 85 DAT (flowering) (Table 2). At 7 DAT (TF), the subsurface roots were small and there was no significant difference between the two treatments. Then, at $47 \mathrm{DAT}(\mathrm{PF})$, the DM and length of subsurface roots with straw incorporation were significantly lower than those in the no-straw treatment. However, when 85 DAT (flowering) was reached, both the DM and length of subsurface roots were significantly greater in pots with straw incorporation than in the nostraw pots $(P<0.05)$.

Whether or not straw was incorporated, the DM and length of total roots grew with time and reached their highest values at 85 DAT (flowering) (Table 2). At 7 DAT (TF), straw incorporation significantly increased the DM of the total roots by $22.2 \%$ and the length of the total roots by $29.5 \%$, compared to the no-straw treatment. At $47 \mathrm{DAT}$ $(\mathrm{PF})$, there was no significant difference between the two straw treatments. However, by 85 DAT (flowering), the DM and length of total roots in pots with straw incorporation were again significantly higher than those in the no-straw treatment $(P<0.05)$.

\section{Fertilizer $\mathbf{N}$ recovery in plants, residual rate in soil and loss rate of each split ${ }^{15} \mathrm{~N}$}

In both straw treatments, the $\mathrm{FNR}_{\mathrm{p}}$ of the BF increased with time and was at its maximum at 130 DAT (maturity) (Table 3). When sampled at 14 DAT and 54 DAT, the FNR of $\mathrm{BF}$ in the straw-incorporation treatment had decreased considerably compared with the no-straw treatment. From 54 DAT to 130 DAT (maturity), the FNR of BF with straw incorporation showed greater increment than the no-straw treatment; this suggests that the uptake of $\mathrm{BF}$ was delayed by the incorporation of wheat straw. However, the FNR decrease rate caused by straw incorporation in the early stage (before 54 DAT) was more pronounced than the $\mathrm{FNR}_{\mathrm{p}}$ increase rate caused by straw incorporation from 54 DAT $^{\mathrm{p}}$ onward. Consequently, at maturity (130 DAT), the $\mathrm{FNR}_{\mathrm{p}}$ of $\mathrm{BF}$ with straw incorporation was $37.8 \%$ lower than in the no-straw treatment significantly $(P<0.05)$.

The FNR of each top-dressing (TF and PF) is also shown in Table 3. In both straw treatments, the top-dressing was mainly absorbed within 7 days of its application (maximum $\mathrm{FNR}_{\mathrm{p}}$ of $\mathrm{PF}$ and about $80 \%$ of maximum $\mathrm{FNR}_{\mathrm{p}}$ of $\mathrm{TF}$ ); the $\mathrm{FNR}_{\mathrm{p}}$ of each top-dressing showed a pronounced decrease from 54 DAT to 130 DAT; and the $\mathrm{FNR}_{\mathrm{P}}$ of PF was significantly higher than TF. In contrast to the $\mathrm{FNR}_{\mathrm{p}}$ of $\mathrm{BF}$, the $\mathrm{FNR}_{\mathrm{p}}$ of top-dressing (both TF and PF) with straw incorporation was significantly higher than in the nostraw treatment $(P<0.05)$. Compared with the no-straw treatment, at maturity the FNR of TF and PF with straw incorporation increased by $34.1 \%$ and $11.1 \%$, respectively.

The ${ }^{15} \mathrm{~N}$ residual rate in soil at maturity for each split is presented in Table 3. In both straw treatments, the residual rates of $\mathrm{TF}$ and $\mathrm{PF}$ were significantly lower than that of $\mathrm{BF}$, and seldom remained in the subsurface soil, indicating that it was difficult for top-dressing $\mathrm{N}$ to be immobilized by the soil. Compared with the residual rate of the no-straw treatment, the residual rate in the strawincorporation treatment increased by $9.1 \%$ and $0.8 \%$ for TF and PF, respectively, markedly lower than the 30.4\% for BF. This suggests that it was difficult for top-dressing $\mathrm{N}$ to be immobilized by straw incorporation.

The ${ }^{15} \mathrm{~N}$ loss rate of each split is shown in Table 3. The order of the average loss rate was: TF $(58.5 \%)>\mathrm{PF}$ $(44.9 \%)>\mathrm{BF}(24.3 \%)$, showing that for top-dressing $\mathrm{N}$ the loss rate was markedly higher than the residual rate (averages of $15.0 \%$ and $12.3 \%$ for TF and PF, respectively). It can be concluded that the $\mathrm{FNR}_{\mathrm{p}}$ of top-dressing was affected mainly by the loss rate rather than by the residual rate. The ${ }^{15} \mathrm{~N}$ loss rate with straw incorporation was lower than in the no-straw treatment for all three splits.

\section{DISCUSSION}

\section{Effects of straw incorporation on rice growth (shoot DM and TN, total root DM and length)}

Our study found that, in both the no-straw treatment and straw-incorporation treatment, shoot TN reached its maximum at 85 DAT (flowering) and dropped slightly toward the end of the season (Fig. 2). This was consistent with many studies where researchers had reported that shoot TN declined after the flowering stage (Wetselaar and Farquhar, 1980; Mikkelsen, 1987; Francis et al., 1993; Guindo et al., 1994; Bufogle et al., 1997; Raun and Johnson, 1999; Eagle et al., 2001; Belder et al., 2005). This phenomenon could be owing to that, while in late stage, $\mathrm{N}$ uptake being unable to offset the $\mathrm{N}$ loss. The $\mathrm{N}$ loss has been explained by mechanisms such as translocation to roots and soil, loss of plant material and gaseous losses from plants (Wetselaar and Farquhar, 1980; Takahashi and Yagi, 2002). However, many researchers have also reported that the increase in shoot TN continued until much later in the rice season or even until maturity (De-datta et al., 1988; Bufogle et al., 1997; Takahashi and Yagi, 2002; Acquaye and Inubushi, 2004). This discrepancy in the timing of maximum shoot TN may be due to differences in soil $\mathrm{N}$ 
availability over the growing season, use of different rice varieties, climatic differences or the different lengths of the growing seasons (Eagle et al., 2001).

Huang and Broadbent (1989) reported that, when sampled at panicle initiation and maturity, shoot DM in the strawincorporation treatment was $20.5 \%$ and $32.6 \%$ lower, respectively, than in the no-straw treatment. Kongchum et al. (2007) and Villegas-Pangga (2009) reported that straw incorporation resulted in reduced shoot TN and DM in the early stage but increased by maturity. Phongpan and Mosier (2003ab) reported that, at maturity, the shoot TN was slightly and insignificantly lower when straw was incorporated. These studies suggest that straw incorporation has a negative effect on rice shoots in the early stage but has a variety of effects at maturity. The negative effects of straw incorporation in the early stage have been explained by $\mathrm{N}$ starvation (Fig. 3), toxic substances and intensely reducing conditions caused by straw decomposition (Tanaka and Nishida, 1996; Cucu et al., 2014). The variety of effects of straw incorporation at maturity are probably due to the differences in soil $\mathrm{N}$ availability; $\mathrm{N}$ fertilizer level and application method; the amount and method of straw incorporated; or the length of the growing season.

At the early-stage sampling (14, 47 and 54 DAT) in our study, the shoot DM and TN were significantly smaller when straw was incorporated. However, when sampled at 7 DAT, we found that even though shoot TN had decreased markedly by straw incorporation (Fig. 2), there was no significant difference in shoot DM between the two treatments (Fig. 1); at 7 DAT, straw incorporation even significantly increased the DM and length of total roots (Table 2). Huang and Broadbent (1989) reported that, when sampled at sixth-leaf stage, straw incorporation had no effect on shoot DM. Tanaka and Nishida (1996) reported that, when sampled at $16 \mathrm{DAT}$, the DM of shoots with straw incorporation decreased by $28.5 \%$, but that the total root DM increased by $9.8 \%$ compared with the no-straw treatment. These phenomena suggest that the negative effect of straw decomposition on rice shoots or total roots was not apparent immediately after straw incorporation. This may be for two reasons. (1) The accumulation of toxic substances and intensely reducing conditions caused by straw decomposition had not become serious at the start of the early stage. (2) The demand for $\mathrm{N}$ at the rice seeding stage is so small that it is not affected by the $\mathrm{N}$ immobilization of straw decomposition; appropriate $\mathrm{N}$ deficiency stress may even stimulate the growth of rice root systems (Fig. 3).

At the late-stage sampling (85 DAT) of this experiment, straw incorporation significantly promoted total root growth (both DM and length) compared with the nostraw treatment (Table 2). This result was consistent with previous reports (Yang et al., 2004; Suriyagoda et al., 2014). Straw incorporation had little effect on surface root variation of 47-85 DAT, but an apparently positive effect on that of subsurface roots (Table 2). This suggests that the subsurface root development during 47-85 DAT plays an important role in the final positive effect of straw incorporation on total roots.

\section{Effects of straw incorporation on surface roots (DM and length)}

When sampled at 85 DAT (flowering), the DM and length of surface roots in our study were significantly greater in the straw-incorporation treatment (Table 2), consistent with Teng et al. (2014). However, Yao et al. (2015) reported that the surface root DM was greater but the length was less for the treatment where all straw was incorporated than in the treatment where no straw was incorporated. This difference may be because of the following. (1) The sampling time in our study was at the flowering stage. In that of Yao et al., however, it was at harvest time, when many fine roots may have decomposed. (2) In our study, the straw used for incorporation was powdered $(<0.841 \mathrm{~mm})$. There was no such preparation of the straw in the study by Yao et al. If the straw is not powdered before incorporation, it is difficult to separate rice roots from soil and straw in later sampling. We found that fine roots are easily damaged and lost because they intertwine extensively with the straw.

We also found that, when sampled at 7 DAT (TF) and 47 DAT (PF), the DM and length of surface roots were also significantly greater in the treatment with straw incorporation (Table 2). This suggests that straw incorporation promotes surface root growth throughout the rice-growing season. The possible reasons are as follows. (1) Because surface soil can easily exchange $\mathrm{O}_{2}$ and $\mathrm{CO}_{2}$ with outside, the redox conditions of the surface soil should not be as sensitive as the subsurface soil when straw is incorporated. This may mean that the surface soil is selected for rice root development. (2) Straw application may release large amounts of K (Fageria and Baligar, 2005) and improve soil physical characteristics such as reducing bulk density, compaction and penetration resistance (Fageria and Baligar, 2005; Gangwar et al., 2006); all of these advantages may promote the growth of rice roots.

We also found many rice roots in the water-soil interface in both straw treatments. In consideration of the vertical distribution of rice roots that could be expressed by exponential equation (Cai et al., 2003; Zhang et al., 2013), we think that the positive effect of straw incorporation on the outermost part of the surface roots may be more pronounced. 


\section{Effects of straw incorporation on subsurface roots (DM and length)}

When sampled at $85 \mathrm{DAT}$ (flowering), the DM and length of subsurface roots were significantly higher in the strawincorporation treatment (Table 2), consistent with Teng et al. (2014). However, Yao et al. (2015) also reported that the subsurface root DM was greater but that the length was less in the treatment where all straw was incorporated than in the no-straw treatment.

Unlike the surface roots, the DM and length of subsurface roots with straw incorporation were significantly less than in the no-straw treatment when sampled at 47 DAT (PF) (Table 2). This suggests that the effect of straw incorporation on the growth of subsurface roots varied with time. There are three possible reasons for this. (1) In the early stage of growth, intensely reducing conditions as a result of straw decomposition likely restricted the growth of subsurface roots; however, in the late stage (as the straw decomposition rate was falling), there were no longer significant differences in the redox conditions between the two straw treatments (Gao et al., 2004; Cucu et al., 2014). Olk et al. (2007) reported that the decomposition of crop residues in a field trial was largely completed after 6 weeks of incorporation. (2) The decomposition of crop straw with a large $\mathrm{C}$ : $\mathrm{N}$ ratio often results in a net $\mathrm{N}$ immobilization phase followed by a net re-mineralization phase (Kanamori and Yasuda, 1979; Azam et al., 1991; Cucu et al., 2014). (3) The advantages of straw incorporation, such as releasing $\mathrm{K}$ and improving soil physical characteristics, may not be apparent in the improvement of subsurface root growth until the late stage, when the disadvantages of straw decomposition have been alleviated.

\section{Effects of straw incorporation on ${ }^{15} \mathrm{~N}$ absorption of base fertilizer (BF)}

In comparison with the no-straw treatment, the ${ }^{15} \mathrm{~N}$ absorption of BF by rice shoots with straw incorporation was significantly smaller in the early-stage samplings (14 and 54 DAT), but showed a larger increment in the late stage (54-130 DAT) (Table 3). This suggests that the uptake of $\mathrm{BF}$ was delayed by the incorporation of wheat straw.

The delay in the ${ }^{15} \mathrm{~N}$ absorption of $\mathrm{BF}$, caused by straw incorporation, has been attributed to: (1) the decomposition of straw immobilizing ${ }^{15} \mathrm{~N}$ in the early stage and then remineralizing available ${ }^{15} \mathrm{~N}$ toward the late stage (Kanamori and Yasuda, 1979; Said-pullicino et al., 2014); (2) the toxic substances and intensely reducing conditions resulting from straw decomposition, which decreased root activity and growth in the early stage, while these inhibitions are alleviated in the late stage (Tanaka and Nishida, 1996; Gao et al., 2004). Additionally, after considering the different effects of straw incorporation on surface and subsurface roots at early-stage sampling (47 DAT) in our experiment (Table 2), we think that the apparent negative effect of straw incorporation on root growth is actually a decrease in subsurface roots.

It is known that once fertilizer $\mathrm{N}$ is incorporated into paddy soil, it is immobilized, and moving between the soil layers is difficult (Linquist et al., 2009) (Table 3), so the subsurface roots play an important role in the ${ }^{15} \mathrm{~N}$ absorption of $\mathrm{BF}$. Hence, straw incorporation can prevent plants from exploring the $\mathrm{BF}{ }^{15} \mathrm{~N}$ in subsurface soil by decreasing the subsurface roots in the early stage, but allows plants to make full use of $\mathrm{BF}{ }^{15} \mathrm{~N}$ in subsurface soil by promoting more subsurface roots in the late stage. According to Huang and Broadbent (1989), there was no delay in $\mathrm{BF}{ }^{15} \mathrm{~N}$ absorption when straw was applied. We think the cause of this might be that $\mathrm{BF}{ }^{15} \mathrm{~N}$ was applied to a soil depth of only $4 \mathrm{~cm}$ in that experiment, so the late-stage development of subsurface roots had no effect on $\mathrm{BF}^{15} \mathrm{~N}$ absorption.

However, researchers (Broadbent and Nakashima, 1965; Broadbent, 1966; Cucu et al., 2014) have reported that (once being immobilized by decomposition of straw with a high C: $\mathrm{N}$ ratio), fertilizer ${ }^{15} \mathrm{~N}$ will be difficult to remineralize, so that late-stage net re-mineralization cannot offset the early-stage net immobilization even after months or seasons. Consequently, lower $\mathrm{FNR}_{\mathrm{p}}$ and a higher residual rate are inevitable when straw is incorporated (Masayna et al., 1985; Huang and Broadbent, 1989). The results of our study support this conclusion (Table 3).

\section{Effects of straw incorporation on ${ }^{15} \mathrm{~N}$ absorption of top-dressing (TF and PF)}

In this study, and consistent with the reports of other researchers, rice absorption of top-dressing ${ }^{15} \mathrm{~N}$ mainly occurred within 7 days after its application and some ${ }^{15} \mathrm{~N}$ was lost before maturity (Table 3) (Guindo et al., 1994; Wilson et al., 1994; Takahashi and Yagi, 2002), and the $\mathrm{FNR}_{\mathrm{p}}$ was higher when top-dressing was applied in the late stage rather than in the early stage (Table 3) (Ghaley et al., 2010; Lin et al., 2014; Hu et al., 2018). Straw incorporation did not affect any of these findings.

Straw incorporation significantly increased the FNR of top-dressing (Table 3). This phenomenon may have two causes. (1) The top-dressing $\mathrm{N}$ is broadcasted into the floodwater and seldom moves downward into the subsurface soil (Table 3) (Phongpan and Mosier, 2003a; Linquist et al., 2009). This means that the top-dressing $\mathrm{N}$ is easily lost (via ammonia volatilization and denitrification) but difficult to be immobilized (by the soil and straw incorporation) (Table 3), and also means that its absorption has a close relationship with the surface roots. (2) The surface roots were increased by straw incorporation. 
Increased surface roots in the soil allowed the rice plant to absorb top-dressing $\mathrm{N}$ more quickly and to compete with $\mathrm{N}$ loss more effectively, and finally to obtain a greater topdressing FNR; this was also why, in the experiment, the $\mathrm{FNR}_{\mathrm{p}}$ of the PF was higher than that of the TF (Table 3).

\section{CONCLUSIONS}

This study was designed to investigate the effect and mechanism of straw incorporation on the absorption of fertilizer $\mathrm{N}$ applied in split applications and on the growth of shoots and roots in the rice-growing season. Straw incorporation significantly decreased the shoot DM and TN in the early-stage but the negative effects were alleviated $(\mathrm{TN})$ or even reversed $(\mathrm{DM})$ in the late stage. It also had a negative effect on the FNR of BF by increasing the ${ }^{15} \mathrm{~N}$ residual rate in soil but had ${ }^{\mathrm{p}}$ a positive effect on the $\mathrm{FNR}_{\mathrm{p}}$ of top-dressing by benefitting the growth of surface roots. Correct management of split $\mathrm{N}$ application is clearly essential: in changing from straw removal to straw incorporation it is necessary to review the $\mathrm{N}$ level not only of BF but also of the top-dressing, and so to better synchronize $\mathrm{N}$ supply with rice demand.

A limitation of this study was the small size of the straw incorporated, being $<0.841 \mathrm{~mm}$ and so much finer than in normal farm practice ( $>5 \mathrm{~cm}$ length). Small straw particles can protect fine roots from being injured and lost in the root sampling that separates the fine roots from the straw, but may also have had a different effect on straw decomposition and rice growth.

\section{ACKNOWLEDGMENTS}

This research was supported by the National Major Research and Development Program of China (No. 2017YFD0800105) and the Agricultural Science and Technology Innovation Foundation of Jiangsu Province CX(15)1002.

\section{Authors' contributions}

Jicheng Zheng contributed to the conception \& data analyses of the study and wrote the manuscript. Dejian Wang contributed significantly to the manuscript preparation. Gang Zhang, Caozhi Qiang, Dezhi Yan and Can Wang participated in the coordination of experimental work \& data collection greatly. All authors read and approved the final manuscript.

\section{REFERENCES}

Acquaye, S. and K. Inubushi. 2004. Comparative effects of app1ication of coated and non-coated urea in clayey and sandy paddy soil microcosms examined by the ${ }^{15} \mathrm{~N}$ tracer technique: I. Effects on growth, $\mathrm{N}$ uptake, and yield of rice crop. Soil Sci. Plant Nutr. 50: 205-213.

Azam, F., M. Ashraf, A. Lodhi and M. Sajjad. 1991. Relative significance of soil and nitrogenous fertilizer in nitrogen nutrition and growth of wetland rice (Oryza sativa L.). Biol Fertil. Soils, 11: $57-61$.

Belder, P., B. A. M. Bouman, J. H. J. Spiertz, S. Peng, A. R. Castaneda and R. M. Visperas. 2005. Crop performance, nitrogen and water use in flooded and aerobic rice. Plant. Soil, 273: 167-182.

Broadbent, F. E. 1966. Interchange between inorganic and organic nitrogen in soils. Hilgardia, 37: 165-180.

Broadbent, F. E. and T. Nakashima. 1965. Plant recovery of immobilized nitrogen in greenhouse experiments. Soil Sci. Soc. Am. J. 29: 55-60.

Bufogle, A., J. L. Kovar, P. K. Bollich, R. J. Norman, C. W. Lindau and R E. Macchiavelli. 1997. Rice plant growth and nitrogen accumulation in drill-seeded and water-seeded culture. Soil Sci. Soc. Am. J. 61: 832-839.

Cai K. Z., S. M. Luo and S. S. Duan. 2003. The relationship between spatial distribution of rice root system and yield. J. South China Agric. Univ. 24: 1-4.

Chen, Y., C. Wu, X. Tang, S. Yang, J. Wang. 2010. Fate of nitrogen from organic and inorganic sources in rice-wheat rotation cropping system. Agric. Sci. China, 9: 1017-1025.

Cucu, M. A., D. Said-Pullicino, V. Maurino, E. Bonifacio, M. Romani and L. Celi. 2014. Influence of redox conditions and rice straw incorporation on nitrogen availability in fertilized paddy soils. Biol. Fertil. Soils, 50: 755-764.

De-Datta, S. K., M. I. Samson, W. Kai-Rong and R. J. Buresh. 1988. Nitrogen use efficiency and nitrogen-15 balances in broadcastseeded flooded and transplanted rice. Soil Sci. Soc. Am. J. 52: 849-855.

Eagle, A. J., J. A. Bird, J. E. Hill, W. R. Horwath and C. Van-Kessel. 2001. Nitrogen dynamics and fertilizer use efficiency in rice following straw incorporation and winter flooding. Agron. J. 93: 1346-1354.

Fageria, N. K. and V. C. Baligar. 2005. Enhancing nitrogen use efficiency in crop plants. Adv. Agron. 88: 97-185.

Fageria, N. K., N. A. Slaton and V. C. Baligar. 2003. Nutrient management for improving lowland rice productivity and sustainability. Adv. Agron. 80: 63-152.

Francis, D. D., J. S. Schepers and M. F. Vigil. 1993. Post-anthesis nitrogen loss from corn. Agron. J. 85: 659-663.

Gangwar, K. S., K. K. Singh, S. K. Sharma and O. K. Tomar. 2006. Alternative tillage and crop residue management in wheat after rice in sandy loam soils of indo-gangetic plains. Soil Tillage Res. 88: 242-252.

Gao, S. D., K. K. Tanji and S. C. Scardaci. 2004. Impact of rice straw incorporation on soil redox status and sulfide toxicity. Agron. J. 96: 70-76.

Ghaley, B. B., H. Høgh-Jensen and J. L. Christiansen. 2010. Recovery of nitrogen fertilizer by traditional and improved rice cultivars in the Bhutan Highlands. Plant Soil. 332: 233-246.

Guindo, D., R. Norman and B. Wells. 1994. Accumulation of fertilizer Nitrogen-15 by rice at different stages of development. Soil Sci. Soc. Am. J. 58: 410-415.

$\mathrm{Hu}$, A., T. Tang anfd Q. Liu. 2018. Nitrogen use efficiency in different rice-based rotations in southern China. Nutr. Cycl Agroecosystems. 112: 75-86.

Huang, Z. and F. Broadbent. 1989. The influences of organic residues on utilization of urea-N by rice. Fertil. Res. 18: 213-220. 
Kanamori, T. and T. Yasuda. 1979. Immobilization, mineralization and the availability of the fertilizer nitrogen during the decomposition of the organic matters applied to the soil. Plant Soil. 52: 219-227.

Koffi, D., B. B. Vincent and M. C. Valere. 2016. Effect of nitrogen fertilizer on yield and nitrogen use efficiency of four aromatic rice varieties. Emirates J. Food and Agric. 28: 126-135.

Kongchum, M., R. D. De-Laune, W. H. Hudnall and P. K. Bollich. 2007. Effect of straw incorporation on ${ }^{15} \mathrm{~N}$-labeled ammonium nitrogen uptake and rice growth. Commun. Soil Sci. Plant Anal. 38: 2149-2161.

Lin, J. J., G. H. Li, L. H. Xue, W. J. Zhang, H. G. Xu, S. H. Wang, L. Z. Yang and Y. F. Ding. 2014. Subdivision of nitrogen use efficiency of rice based on ${ }^{15} \mathrm{~N}$ tracer. Acta Agrono. Sin. 40: 1424-1434.

Linquist, B. A., J. E. Hill, R. G. Mutters, C. A. Greer, C. Hartley, M. D. Ruark and V. K. Chris. 2009. Assessing the necessity of surfaceapplied preplant nitrogen fertilizer in rice systems. Agron. J. 101: 906-915.

Lu, R. K. 2000. Soil Agro-Chemical Analysis. Agriculture Technology Press, Beijing, China.

Masayna, W., H. Kai and S. Kawaguchi. 1985. Nitrogen behavior in tropical wetland rice soils. 2. The efficiency of fertilizer nitrogen, priming effect and A-values. Fertil. Res. 6: 37-47.

Mikkelsen, D. S. 1987. Nitrogen budgets in flooded soils used for rice production. Plant Soil. 100: 71-97.

Olk, D. C., M. I. Samson and P. Gapas. 2007. Inhibition of nitrogen mineralization in young humic fractions by anaerobic decomposition of rice crop residues. Eur. J. Soil Sci. 58: 270-281.

Phongpan, S. and A. R. Mosier. 2003a. Effect of crop residue management on nitrogen dynamics and balance in a lowland rice cropping system. Nutr. Cycl. Agroecosystems. 66: 133-142.

Phongpan, S. and A. R. Mosier. 2003b. Effect of rice straw management on nitrogen balance and residual effect of urea- $\mathrm{N}$ in an annual lowland rice cropping sequence. Biol. Fertil. Soils. 37: 102-107.

Raun, W. R. and G. V. Johnson. 1999. Improving nitrogen use efficiency for cereal production. Agron. J. 91: 357-363.

Said-Pullicino, D., M. A. Cucu, M. Sodano, J. J. Birk, B. Glaser and L. Celi. 2014. Nitrogen immobilization in paddy soils as affected by redox conditions and rice straw incorporation. Geoderma. 228: 44-53.

Standardization Administration of the People's Republic of China. 2009. Classification and Codes for Chinese Soil. Standards Press of China, Beijing, China.

Suriyagoda, L., W. A. De-Costa and H. Lambers, H. 2014. Growth and phosphorus nutrition of rice when inorganic fertiliser application is partly replaced by straw under varying moisture availability in sandy and clay soils. Plant Soil. 384: 53-68.

Takahashi, S. and A. Yagi. 2002. Losses of fertilizer-derived N from transplanted rice after heading. Plant Soil. 242: 245-250.

Tanaka, F. and M. Nishida. 1996. Inhibition of nitrogen uptake by rice after wheat straw application determined by tracer $\mathrm{NH}_{4}{ }^{+}-{ }^{15} \mathrm{~N}$. Soil Sci. Plant Nutr. 42: 587-591.

Teng, X. L., W. M. Deng, M. M. Sun, K. L. Liu and Y. Z. Li. 2014.
Effects of simplified cultivation and returning-straw-to-field on yield and root traits of rice. Acta Agric. 26: 1-7.

Tiwari, S., U. C. Dumka, P. K. Hopke, P. Tunved, A. K. Srivastava, D. S. Bisht and R. K. Chakrabarty. 2016. Atmospheric heating due to black carbon aerosol during the summer monsoon period over Ballia: A rural environment over indo-gangetic plain. Atmos. Res. 178: 393-400.

Villegas-Pangga, G. 2009. Growth and yield of rice (Oryza sativa L.) applied with straw from different rice varieties under varying water regimes and fertilizer levels. Philipp. J. Crop Sci. 34: 59-67.

Wang, S. J., J. Y. Wang and Y. Chen. 2004. A three-year research on nitrogen recovery of chemical fertilizer and rice straw by isotope ${ }^{15} \mathrm{~N}$ in rice fields. Chin. J. Soil Sci. 35: 763-766.

Wang, W., C. Cai, S. K. Lam, G. Liu and J. Zhu. 2018. Elevated $\mathrm{CO}_{2}$ cannot compensate for japonica grain yield losses under increasing air temperature because of the decrease in spikelet density. Eur. J. Agron. 99: 21-29.

Wetselaar, R. and G. D. Farquhar. 1980. Nitrogen losses from tops of plants. Adv. Agron. 33: 263-302.

Wilson, C., B. Wells and R. Norman. 1994. Fertilizer nitrogen uptake by rice from urea-ammonium nitrate solution vs granular urea. Soil Sci. Soc. Am. J. 58: 1825-1828.

Xia, L., S. Wang and X. Yan. 2014. Effects of long-term straw incorporation on the net global warming potential and the net economic benefit in a rice-wheat cropping system in China. Agric. Ecosyst. Environ. 197: 118-127.

Xia, L., S. K. Lam, B. Wolf, R. Kiese, D. Chen and K. Butterbach-Bahl. 2018. Trade-offs between soil carbon sequestration and reactive nitrogen losses under straw return in global agroecosystems. Glob. Change Biol. 24: 5919-5932.

Yadvinder, S., S. Bijayand J. Timsina. 2005. Crop residue management for nutrient cycling and improving soil productivity in rice-based cropping systems in the tropics. Adv. Agron. 85: 269-407.

Yang, C., L. Yang, Y. Yang and Z. Ouyang. 2004. Rice root growth and nutrient uptake as influenced by organic manure in continuously and alternately flooded paddy soils. Agric. Water Manag. 70: $67-81$

Yang, G., K. Chu, H. Tang, Y. Nie and X. Zhang. 2013. Fertilizer ${ }^{15} \mathrm{~N}$ accumulation, recovery and distribution in cotton plant as affected by $\mathrm{N}$ rate and split. J. Integr. Agric. 12: 999-1007.

Yao, S., X. Teng and B. Zhang. 2015. Effects of rice straw incorporation and tillage depth on soil puddlability and mechanical properties during rice growth period. Soil Tillage Res. 146: 125-32.

Yu, J. 2012. Effects of Combined Application of Inorganic and Organic Fertilizers on Growth and Nitrogen Uptake. (Master's Thesis), Nanjing Agricultural University, China. p17-31.

Zhang, L., Y. Liu and L. Hao. 2016. Contributions of open crop straw burning emissions to $\mathrm{PM}_{2.5}$ concentrations in China. Environ. Res. Lett. 11: 14014.

Zhang, Y., H. D. Qin, M. Huang, Z. Li, C. L. Yang, N. N. Wang, Q. M. Ji, J. Zhang, L. M. Wu, W. S. Nong, X. P. Dong and L. G. Jiang. 2013. Mathematical simulation of rice root spatial distribution and its application. J. S. China Agric. Univ. 34: 304-308. 